\title{
Increased frequency of bronchial hyperresponsiveness in patients with inflammatory bowel disease
}

\author{
E. Louis ${ }^{1}$, R. Louis ${ }^{2}$, V. Drion ${ }^{1}$, V. Bonnet ${ }^{1}$, A. Lamproye ${ }^{1}$, M. Radermecker ${ }^{2}$, J. Belaiche ${ }^{1}$ \\ Departments of ${ }^{1}$ Gastroenterology and ${ }^{2}$ Pneumology, CHU of Liège, Belgium
}

\begin{abstract}
:
Although bronchopulmonary manifestations are rare in inflammatory bowel diseases (IBD), subclinical abnormalities have been described in up to $50 \%$ of cases. The pathophysiology of these abnormalities remains unknown. However, a latent inflammation of the bronchial mucosa secondary to the inflammation of the intestinal mucosa has been suggested. This subclinical inflammation may lead to increased bronchial responsiveness. We studied the bronchial responsiveness in 38 inflammatory bowel disease (IBD) patients, using the methacholine test. Bronchial hyperresponsiveness was defined by a $\mathrm{PC}_{20} \mathrm{M}<16 \mathrm{mg} / \mathrm{ml}$. Twenty-four healthy

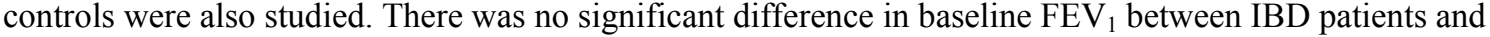
controls. However, there was a significantly greater fall in $\mathrm{FEV}_{1}$ in the IBD patients at the concentrations of methacholine tested. The frequency of bronchial hyperresponsiveness was significantly higher in the IBD population $(45 \%)$ than in controls $(17 \% ; P<0.03)$. Atopy, defined by skin test, was more common in IBD patients $(42 \%)$ than in controls $(21 \%)$. Even when only nonatopic subjects were considered, the frequency of bronchial hyperresponsiveness was significantly higher in IBD patients $(41 \%)$ than in controls $(5 \% ; P<0.02)$. Thus, subclinical bronchial hyperresponsiveness is common in IBD, and may be considered a further extraintestinal manifestation.
\end{abstract}

Clinical bronchopulmonary manifestations have rarely been described in Crohn's disease (CD) or ulcerative colitis (UC) $(3,4,11,13)$. The best known is the hypersensitivity pneumopathy induced by sulfasalazine (17). However, subclinical abnormalities are present in about two-thirds of the patients. These abnormalities concern both the number and the activity of cells obtained after bronchoalveolar lavage (1) and the functional pulmonary parameters such as carbon monoxide-diffusing capacity $(1,6,8)$.

The pathophysiology of these abnormalities is not understood, but the common mucosal immune system has been incriminated (4). Lymphocytes stimulated at one site may home back to other mucosal sites. Thus, subclinical immune activation and inflammation may exist not only in the gastrointestinal mucosa, but also in all mucosae including that of the respiratory tract. Latent inflammation of the bronchial mucosa may lead to increased bronchial responsiveness (5). We have studied the bronchial responsiveness in patients with inflammatory bowel disease (IBD). Furthermore, we looked at the frequency of atopy, a condition known to favor bronchial hyperresponsiveness (2), and one reported, in some studies, to be associated with $\operatorname{IBD}(7,10)$.

Key words: atopy; bronchial hyperresponsiveness; Crohn's disease; ulcerative colitis.

\section{Material and methods}

\section{Patients}

Thirty-eight consecutive patients with IBD were studied (27 CD and 11 UC). These comprised 22 women and 16 men, 18-62 years old (mean age 33.8 \pm 9.5 years). Eleven had a history of clinical manifestation of atopy (five with eczema, three with hay fever, and three with both eczema and hay fever). Eighteen were cigarette smokers. None had a previous history of pulmonary disease, toxic bronchopulmonary exposure, or sinusitis. None had associated diseases such as diabetes mellitus, cardiac failure, or cystic fibrosis. Two patients had a family history of asthma. Physical examination and chest radiographs were normal in all patients at the time of the study. Duration of the IBD at the onset of the study ranged from 1 month to 20 years (mean duration $59 \pm 71$ months).

Among 27 CD patients, five had only small bowel involvement, four had only colon involvement, and 18 had both small and large bowel disease or diffuse intestinal involvement. Six had systemic manifestations: arthralgia (two), arthritis (two), and erythema nodosum (two). Mean ( \pm SEM) Crohn's disease Activity Index (CDAI) was $162 \pm 129(0-468)$. Twelve had active disease (CDAI $>150)$ at the time of the study. Thirteen were treated with 5-ASA (0.75-4 g/day), five with methylprednisolone (24-60 mg/day), four with azathioprine (75-150 mg/day), 
three with azathioprine (0.75-150 mg/day) and methylprednisolone (4-20 mg/day), and two with methylprednisolone (16-32 $\mathrm{mg} /$ day) and metronidazole ( $1.5 \mathrm{~g} /$ day).

Among 11 UC patients, seven had total colonic involvement and four limited left-sided colitis. None had systemic manifestations. Four had active disease (clinical symptoms and endoscopic lesions). Six were treated with 5-ASA (1-3 g/day), one with methylprednisolone ( $20 \mathrm{mg} /$ day), one with sulfasalazine ( $2 \mathrm{~g} /$ day), and three had no treatment.

\section{Control subjects}

The control group included hospital staff and other healthy volunteers. There were 24 control subjects matched for age, sex, and smoking: 14 women and 10 men, 22-40 years old (mean age $25 \pm 4.4$ years), including 10 cigarette smokers. One had a familial history of asthma and three had a personal history of clinical manifestation of atopy (one had eczema and two had hay fever).

Atopy

Atopy was studied with cutaneous prick-testing for classical aeroallergens: Dermatophagoides pteronyssi-nus, grass pollen, tree pollen, weed pollen, cat and dog dander, feathers, and molds. Atopy was considered to be present if at least one aeroallergen produced a wheal higher than $75 \%$ of the histamine control.

\section{Bronchial responsiveness}

Bronchial responsiveness was measured by metha-choline stimulation. Methacholine chloride solutions (biochemicals) were dissolved in saline, stored at $4^{\circ} \mathrm{C}$, and used within 14 days of preparation. The aerosols were delivered by a nebulizer (Hudson) containing $3 \mathrm{ml}$ of solution and driven by compressed air at $81 / \mathrm{min}$. Under these conditions, the nebulizer had an output of $0.3 \mathrm{ml} / \mathrm{min}$ and generated an aerosol with particles of $2 \mu \mathrm{m}$ median diameter. After baseline $\mathrm{FEV}_{1}$ measurement, subjects inhaled an aerosolized saline solution by tidal breathing for $2 \mathrm{~min}$. FEV ${ }_{1}$ was measured $3 \mathrm{~min}$ after the saline and was considered the control value. Provided this $\mathrm{FEV}_{1}$ had not fallen to less than $95 \%$ of baseline value, a methacholine challenge was carried out. Subjects successively inhaled a methacholine solution of 1,4 , and $16 \mathrm{mg} / \mathrm{ml}$ every $3 \mathrm{~min}$. $\mathrm{FEV}_{1}$ was measured 30 and $90 \mathrm{~s}$ after each concentration from a forced-flow volume curve (Jaeger flow screen). The test was stopped if FEV fell $_{1}$ to less than $80 \%$ of the control value recorded. In this case, the $\mathrm{PC}_{20} \mathrm{M}$ was read from the log dose-response curve by linear interpolation. Bronchial hyperresponsiveness was defined as a $\mathrm{PC}_{20} \mathrm{M}$ less than $16 \mathrm{mg} / \mathrm{ml}$.

\section{Statistical methods}

Results were expressed as mean \pm SEM. The two-tailed $t$-test or chi-square analysis was used for comparison of data between patients and controls.

\section{Results}

Atopy

Five out of 24 controls had at least one positive skin reaction, including the three with history of atopy. The frequency of the positive reactions was as follows: $D$. pteronyssinus $(4 / 5)$, tree pollen $(3 / 5)$, grass pollen $(1 / 5)$, and molds (1/5). There were several positive reactions in three subjects. Sixteen out of 38 IBD patients had at least one positive reaction with the prick test, including the 11 with history of atopy. The frequency of positive tests was as follows: grass pollen $(8 / 16), D$. pteronyssinus $(7 / 16)$, cat dander $(7 / 16)$, tree pollen $(6 / 16)$, feathers $(3 / 16)$, dog dander $(2 / 16)$, weed pollen $(2 / 16)$, and molds $(2 / 16)$. Eleven patients were simultaneously reactive to more than one aeroallergen. Thus, the proportion of atopy tended to be higher in the IBD group than in the control group $(P<0.10)$.

\section{Bronchial responsiveness}

There was no significant difference in basal $\mathrm{FEV}_{1}$ between patients and controls $(98+1.99 \%$ of predicted value in control vs $102 \pm 1.3 \%$ in IBD). The mean fall in $\mathrm{FEV}_{1}$ in patients and controls is shown in Fig. $1 . \mathrm{FEV}_{1}$ fell by $6.11 \pm 0.99 \%(n=38)$ and $1.31 \pm 0.96 \%(n=24)$ after $1 \mathrm{mg} / \mathrm{ml}$ of methacholine $(P<0.002), 11.7 \pm 1.58 \%(n=37)$ and $5.7 \pm 1.17 \%(n=24)$ after $4 \mathrm{mg} / \mathrm{ml}$ of methacholine $(P<0.008)$, and $14.8 \pm 1.41 \%(n=29)$ and $11.84 \pm 1.48$ $(n=23)$ after $16 \mathrm{mg} / \mathrm{ml}$ of methacholine $(P<0.06)$ in patients and controls, respectively. The number of patients 
tested with 4 and $16 \mathrm{mg} / \mathrm{ml}$ was smaller than with $1 \mathrm{mg} / \mathrm{ml}$ because some had already had a fall $>20 \%$ in $\mathrm{FEV}$. $_{\text {. }}$ The frequency of bronchial hyperrespon-siveness $\left(\mathrm{PC}_{20} \mathrm{M}<16 \mathrm{mg} / \mathrm{ml}\right)$ was significantly higher in IBD patients $(17 / 38)$ than in controls $(4 / 24)(P<0.03)$. Mean $\mathrm{PC}_{20} \mathrm{M}$ in patients with bronchial hyperresponsiveness was 7.04 $\pm 1.21 \mathrm{mg} / \mathrm{ml} v s 9.4 \pm 2.48 \mathrm{mg} / \mathrm{ml}$ in controls with bronchial hyperresponsiveness $(P<0.2)$.

Fig. 1. Fall in FEV $V_{1}$ (mean \pm SEM) after inhalation of 1, 4, and $16 \mathrm{mg} / \mathrm{ml}$ of methacholine in IBD patients (-) and controls $(\square)$. $* P<0.008 ; * * P<0.002$.

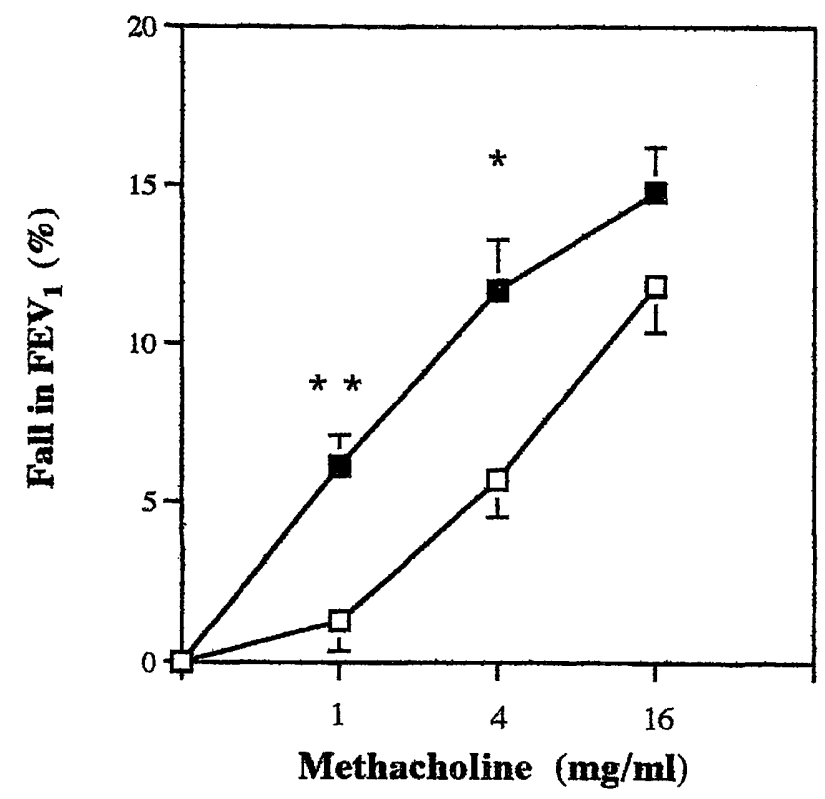

Fig. 2. Distribution of fall in FEV $V_{l}$ after inhalation of $4 \mathrm{mg} / \mathrm{ml}$ of methacholine in nonatopic IBD patients and nonatopic controls.

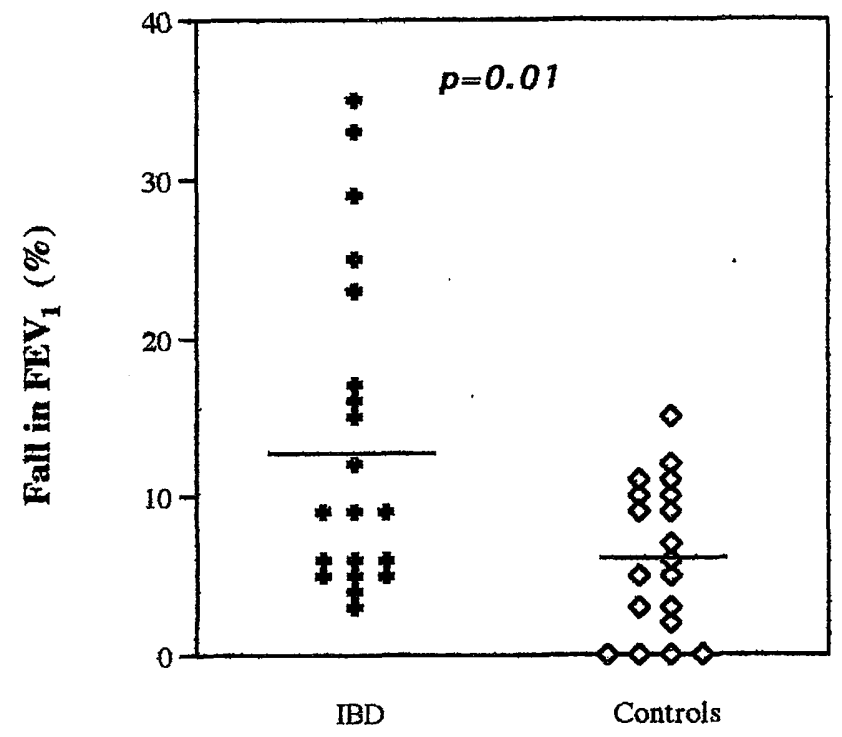


The frequency of bronchial hyperresponsiveness, and the fall in $\mathrm{FEV}_{1}$ after $4 \mathrm{mg} / \mathrm{ml}$ of methacholine were compared in different subgroups of controls and patients. Bronchial hyperresponsiveness was significantly associated with atopy in the controls: $3 / 5$ atopic control subjects had bronchial hyperresponsiveness vs 1/19 nonatopic $(P<0.02)$. In contrast, atopy was not significantly associated with bronchial hyperresponsiveness in IBD: $8 / 16$ atopic IBD patients vs $9 / 22$ nonatopic had bronchial hyperresponsiveness. The mean fall in $\mathrm{FEV}_{1}$ after $4 \mathrm{mg} / \mathrm{ml}$ of methacholine in atopic control subjects $(10.1 \pm 3.6 \%)$ was significantly greater than in nonatopic subjects $(4.51 \pm 1.04 \%)(P<0.05)$. In contrast, there was no significant difference between atopic $(10.5 \pm 2.2 \%)$ and nonatopic $(12.62 \pm 2.25 \%)$ IBD patients. Considering only the nonatopic subjects in each group, the mean falls in $\mathrm{FEV}_{1}$ were $5.86 \pm 1.01 \%(n=21)$ and $1.91 \pm 0.76 \%(n=19)$ after $1 \mathrm{mg} / \mathrm{ml}$ of methacholine $(P<0.004)$, $12.62 \pm 2.25 \%(n=21)$ and $4.51 \pm 1.04 \%(n=19)$ after $4 \mathrm{mg} / \mathrm{ml}$ of methacholine $(P<0.004)($ Fig. 2$)$, and 13.29 $\pm 1.58 \%(n=16)$, and $9.94 \pm 1.42 \%(n=19)$ after $16 \mathrm{mg} / \mathrm{ml}$ of methacholine $(P<0.12)$ in patients and controls, respectively. The proportion of bronchial hyperresponsiveness in nonatopic IBD patients $(9 / 22)$ was significantly higher than that in nonatopic controls $(1 / 19)(P<0.02)$. The mean value of $\mathrm{PC}_{20} \mathrm{M}$ in IBD patients with bronchial hyperresponsiveness was $6.74 \pm 1.61 \mathrm{mg} / \mathrm{ml}$ vs $13.9 \mathrm{mg} / \mathrm{ml}$ in the unique control showing bronchial hyperresponsiveness (Fig. 3).

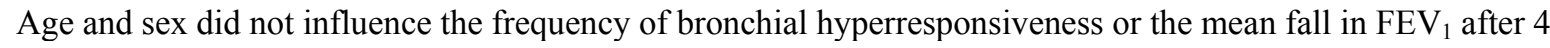
$\mathrm{mg} / \mathrm{ml}$ of methacholine in either patients or controls.

Smoking did not influence the frequency of bronchial responsiveness in either patients or controls. However, there was a trend to a greater fall in $\mathrm{FEV}_{1}$ after $4 \mathrm{mg} / \mathrm{ml}$ of methacholine in smokers compared to nonsmokers both in patients $(15.18 \pm 2.79 \%$ vs $9.24 \pm 1.62 \%)(P=0.11)$ and controls $(9.52 \pm 1.8$ vs $5.21 \pm 1.3 \%)(P=0.06)$. Considering only nonatopic nonsmoker subjects in each group, there was a still greater decrease in $\mathrm{FEV}_{1}$ after methacholine in patients than in controls. The mean falls in $\mathrm{FEV}_{1}$ were, respectively, $4.4 \pm 0.9 \%(n=-10)$ and $0.5 \pm 1.1 \%(n=10)$ after $1 \mathrm{mg} / \mathrm{ml}$ of methacholine $(P<0.02), 9.4 \pm 2.6 \%(n=10)$ and $4.3 \pm 1.3 \%(n=10)$ after 4 $\mathrm{mg} / \mathrm{ml}$ of methacholine $(P=0.1)$, and $12.9 \pm 2.4 \%(n=9)$ and $7.2 \pm 1.6 \%(n=10)$ after $16 \mathrm{mg} / \mathrm{ml}$ of methacholine $(P=0.06)$.

Fig. 3. Distribution of $P C_{20} M$ in atopic and nonatopic IBD patients and atopic and nonatopic controls.

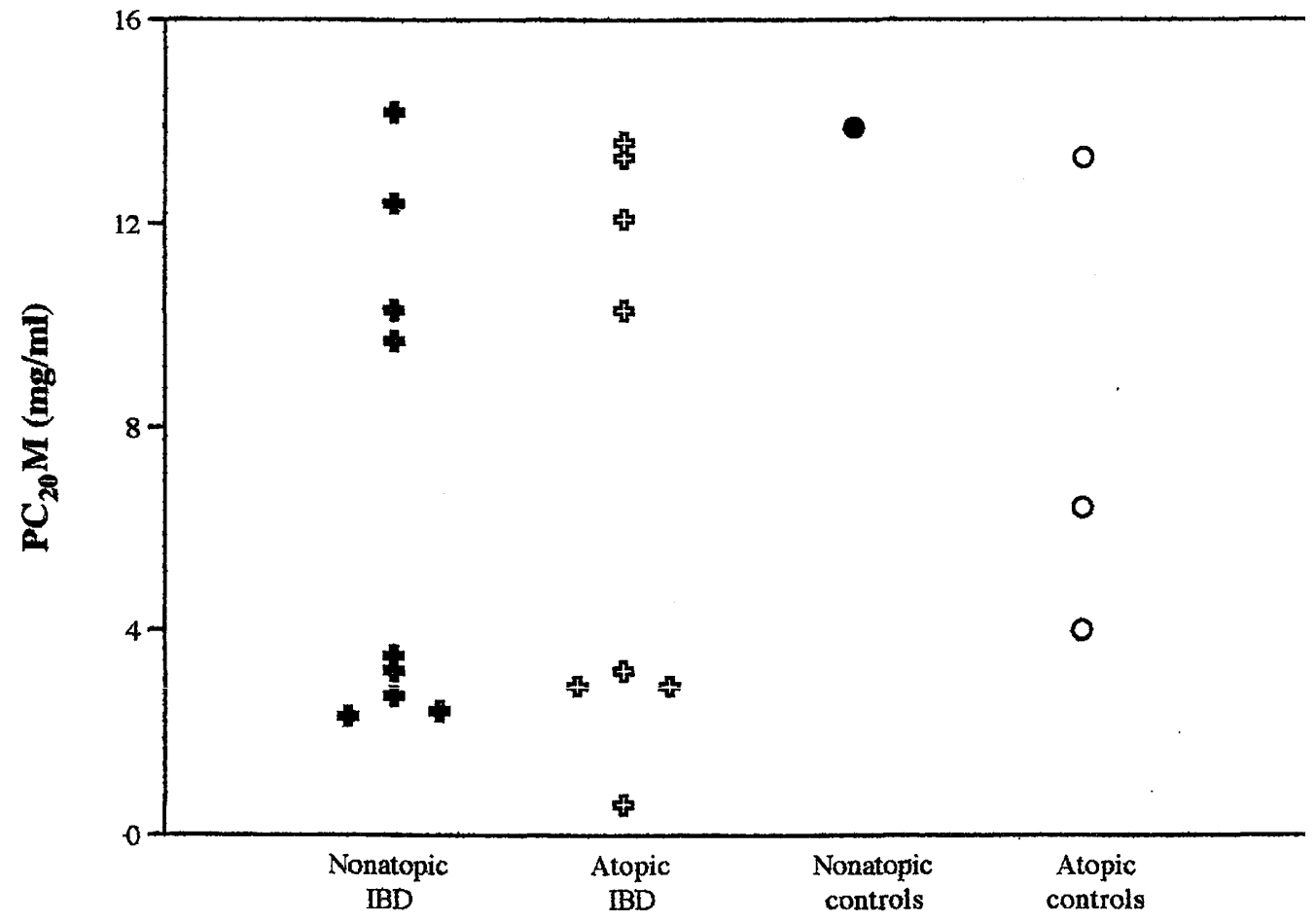


Neither the proportion of bronchial hyperresponsiveness nor the mean fall in $\mathrm{FEV}_{1}$ after $4 \mathrm{mg}$ of methacholine was significantly different between UC $(4 / 11 ; 11.9 \pm 2.8 \%)$ and CD $(13 / 27 ; 12.5 \pm 1.8 \%)$. Furthermore, these two parameters were not influenced by the activity of the disease at the moment of the test, its extent, or its duration. However, in $\mathrm{CD}$, the mean fall in $\mathrm{FEV}_{1}$ after $4 \mathrm{mg} / \mathrm{ml}$ of metha-choline tended to be greater in patients with extraintestinal manifestations of the disease $(18.5 \pm 5.6 \%)$ than in patients without $(9.4 \pm 1.8 \%)(P=0.06)$, and it was significantly greater in patients treated with azathioprine $(21.8 \pm 5.6 \%$ vs $9 \pm 1.4 \%)(P<0.003)$. There was no significant difference between patients treated with corticosteroids $(12.7 \pm 3.6 \%)$ and other patients $(11.4$ $\pm 2.2 \%)$

\section{Discussion}

This study shows increased bronchial responsiveness to methacholine in patients with IBD who had no clinical pulmonary symptoms, normal chest roentgenograms, and normal basal $\mathrm{FEV}_{1}$ measurements. Indeed, $45 \%$ of IBD patients had a $\mathrm{PC}_{20} \mathrm{M}$ smaller than $16 \mathrm{mg} / \mathrm{ml} v s 17 \%$ of control subjects, and the mean fall in $\mathrm{FEV}_{1}$ after various concentrations of methacholine was greater in patients than in controls. This hyperresponsiveness, although definite, was small compared with previous measurements in mild asthmatic subjects (12).

Although mild pulmonary impairments have been previously demonstrated in IBD, most studies have failed to find any difference in basal $\mathrm{FEV}_{l}$ between IBD and control subjects $(1,6,8)$. Our study confirms the absence of difference in basal bronchial caliber between the two groups. However, bronchial responsiveness evaluation is a more sensitive method to detect mild airway dysfunction. As well as in asthma, increased bronchial responsiveness has been described in sinusitis, various bronchopulmonary diseases, toxic bronchopulmonary exposure, diabetes, and cardiac failure (2). These conditions were not present in our patients.

Bronchial hyperresponsiveness has also been described in association with a family history of asthma. However, the two patients with a family history of asthma in our study did not have bronchial hyperresponsiveness. There was no significant difference in bronchial responsiveness between atopic and nonatopic IBD patients, and the difference between IBD patients and controls was still noted if only nonatopic patients were considered. The presence of atopy was determined by skin reaction because it is the more specific method (14). We did not measure the serum IgE levels, and some patients treated by oral steroids may have had false negative skin tests. However, among the patients treated with steroids $(n=11)$ and having negative skin test $(n=6)$, only two had bronchial hyperresponsiveness, which could have been associated with undiscovered atopy. Patients and controls were matched for smoking. Moreover, there was only a mild, nonsignificant difference in the bronchial responsiveness in both patients and controls between smokers and nonsmokers. This may be due to the fact that both controls and patients were young and had only a relatively short exposure to tobacco. Considering only nonatopic, nonsmoker subjects in each group, there was still a greater decrease in $\mathrm{FEV}_{1}$ after various concentrations of methacholine in patients than in controls.

Thus, our study demonstrates that IBD, by itself, favors the development of nonspecific airway hyperresponsiveness. The significance of this phenomenon is not clear. There is strong evidence in the literature of the relationship between airway inflammation and bronchial hyperresponsiveness (5). Inflammation of the small airways may occur in IBD, induced by the bronchial homing of lymphocytes activated in the digestive tract. Alveolar lymphocytosis has been previously described in $\mathrm{CD}$, although not in UC (1). In this perspective, the histopathology of the bronchial mucosa remains to be investigated. Neither the type of IBD nor the extent or activity of disease at the time of study influenced bronchial responsiveness. However, there was a trend to increased bronchial responsiveness in $\mathrm{CD}$ patients with extraintestinal manifestations. As recent genetic studies in IBD suggest disease heterogeneity to be important (15), patients with extraintestinal manifestations may represent a particular subgroup of CD patients. Bronchial responsiveness was also significantly increased in CD patients treated with azathioprine. These patients had chronic active disease and may also represent a subgroup of patients more prone to develop bronchial hyperresponsiveness. However, a side-effect of azathioprine could not be excluded since pneumopathies have been described with this drug (16). Although no decrease in bronchial responsiveness in patients treated with steroids was noted in our study, most of them were treated with relatively low doses, which have been shown to be unable to influence bronchial responsiveness (9).

In conclusion, this study has demonstrated increased bronchial responsiveness in IBD patients with no bronchopulmonary symptoms. This increase occurs independently of the presence of atopy, and may be a consequence of activation of the mucosal immune system. Further studies to elucidate the mechanism that sustains this functional abnormality and to confirm the stronger association with some subgroups of IBD are planned. 
Published in: Allergy (1995), vol. 50, pp. 729-733

Status: Postprint (Author's version)

\section{Acknowledgment}

E. Louis is supported by a Smith Kline Beecham Biologicals grant from the National Fund for Scientific Research, Belgium.

\section{References}

1. BONNIERE P, WALlAERT B, CORTOT A, et al. Latent pulmonary involvement in Crohn's disease: biological, functional, bronchoalveolar lavage and scintigraphic studies. Gut 1986: 27: 919-25.

2. Burney P, Anderson H, Burrows B, Chan Yeung M, Pride N, Speizer F. Epidemiology of airway hyperresponsiveness. In: HoLGATE S, ed. The role of inflammatory processes in airway hyperresponsiveness. Oxford: Blackwell, 1989: 222-50.

3. Butland RJA, COlE P, Citron KM, TuRnER-WARWICK M. Chronic bronchial suppuration and inflammatory bowel disease. Q J Med 1981: 197: 63-75.

4. Calder CJ, Lacy D, RaAfat F, Weller PH, Booth IW. Crohn's disease with pulmonary involvement in a 3-year-old boy. Gut 1993: 34: $1636-8$

5. DJukanovic R, Roche W, Wilson J, et al. Mucosal inflammation in asthma. Am Rev Respir Dis 1990: 142: $434-57$.

6. Eade OE, Smith CL, Alexander JR, Whorwell PJ. Pulmonary function in patients with inflammatory bowel disease. Am J Gastroenterol 1980: 73: 154-6.

7. Hammer B, AShurst P, NAish J. Diseases associated with Crohn's disease and ulcerative colitis. Gut 1968: 9: 17-21.

8. Heatley RV, Thomas E, Prokipchuk J, Gauldie J, SIENEWICZ DJ, Bienenstock J. Pulmonary function abnormalities in patients with inflammatory bowel disease. Q J Med 1982: 203: 241-50.

9. JENKINS CR, WOOLCOCK AJ. Effect of prednisolone and beclomethasone dipropionate on airway responsiveness in asthma: a comparative study. Thorax 1988: 43: 378-84.

10. JeWELl DP, TRUELOVE SC. Reaginic hypersensitivity in ulcerative colitis. Gut 1972: 13: 903-6.

11. Lemann M, Messing B, D'Agay F, Modigliani R. Crohn's disease with respiratory tract involvement. Gut 1987: $28: 1669-72$.

12. LOUIS R, BURY T, CORHAY JL, RADERMECKER MF. Acute bronchial and hematologic effects following inhalation of a single dose of PAF. Comparison between asthmatics and normal subjects. Chest 1994: 106: 1094-9.

13. McKee AL, RAJApaksa A, Kalish PE, PiYchumoni CS. Severe interstitial pulmonary fibrosis in a patient with chronic ulcerative colitis. Am J Gastroenterol 1983: 78: 86-9.

14. PEPYS J. "Atopy": a study in definition. Allergy 1994: 49: 397-9.

15. SATSANGi J, Jewell DP, RosenBerg WMC, Bell JI. Genetics of inflammatory bowel disease. Gut 1994: 35: 696-700.

16. Stetter M, SChMidl M, KRAPF R. Azathioprine hypersensitivity mimicking Goodpasture's syndrome. Am J Kidney Dis 1994: 23: 874-

17. YAFFE BH, KoreLitz BI. Sulfasalazine pneumonitis. Am J Gastroenterol 1983: 78: 493-4. 